\title{
A Comparative Analysis of Determinants of Household Knowledge of Split and Grouped Mosquito Larval Source Management for Malaria Prevention and Control in Rural Malawi
}

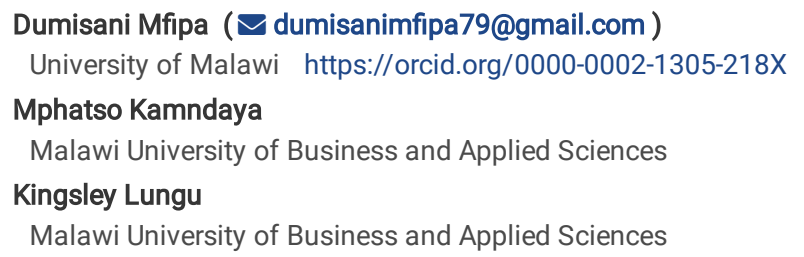

\section{Research}

Keywords: Knowledge, Grouped and Split Larval Source Management Methods

Posted Date: October 4th, 2021

DOI: https://doi.org/10.21203/rs.3.rs-944709/v1

License: @ (i) This work is licensed under a Creative Commons Attribution 4.0 International License. Read Full License 


\section{Abstract}

Background

Limited studies have compared determinants of household knowledge of split and grouped mosquito larval source management (LSM) methods. Thus, we compared determinants of household knowledge of split and grouped mosquito LSM methods for malaria control in Malawi.

Methods

A cross-sectional study was conducted among 479 households in Nthache, Mwanza district, Malawi. Household knowledge of mosquito LSM methods; draining stagnant water, larviciding, clean environment and clearing grass/bushes were assessed by using a validated structured household questionnaire administered to an adult household member. Chi-square test was used to compare the distribution of household knowledge of each of the split and grouped mosquito LSM methods. Multivariable logistic regression was used to examine factors associated with household knowledge of each of the split and grouped mosquito LSM methods.

Results

Household knowledge of draining stagnant water was lower than high-level knowledge of grouped mosquito LSM methods ( $32.9 \%$ versus $83.5 \%$, $p=0.000$ ). Household knowledge of clearing grass/bushes was lower than high-level knowledge of grouped mosquito LSM methods ( $8.2 \%$ versus $77.7 \%$, $p=0.000)$. Household knowledge of clean environment was lower than high-level knowledge of grouped mosquito LSM methods ( $21.8 \%$ versus $63.8 \%$, $p=0.000)$. No significant differences were observed between knowledge of larviciding and high-level knowledge of grouped mosquito LSM methods (4.1\% versus $5.8 \%$, $p=0.421$ ). Respondents without education had $57 \%$ less the odds of having knowledge of draining stagnant water than those with primary education ( $A O R=0.43,95 \% \mathrm{Cl}$ 0.26-0.69). Those from iron-roofed households and the widowed had three and more than four times the odds of having knowledge of larviciding than those from grass-thatched households and the married (AOR=3.03, 95\% Cl 1.26-7.29 and AOR=4.73, 95\% Cl 1.34-16.73), respectively.

Conclusions

Except for larviciding, household knowledge of grouped mosquito LSM methods was significantly higher than split methods. Policy for integrated vector management should address determinants of split mosquito LSM methods to improve household knowledge.

\section{Background}

World Health Organization (WHO) and the global malaria community envisages a world free of malaria [1]. Encouragingly, the burden of malaria continues to decline world-wide due to malaria vector control strategies [2]. These world-wide achievements in malaria control have been attributed to massive investments in vector control over the past decade [3]. Literature suggest that environmental management strategies may be cost-effective as well as may accelerate progress towards malaria elimination [4] as these strategies play an important role in controlling, reducing and eliminating larval habitats. There are a number of mosquito LSM methods for malaria prevention and control including larviciding, biological control and several environmental management strategies such as clearing vegetation, draining surface water, and environmental sanitation [5]. It is, therefore, necessary to assess and compare determinants of household knowledge of split and grouped mosquito LSM methods for proper and effective implementation of larval control programs. More studies have been done to assess determinants of split mosquito LSM methods in sub-Saharan Africa (SSA) and elsewhere. For instance, a western Kenyan study explored knowledge, attitudes and practices of mosquito LSM using quantitative methods [6]. The main strength of the method used in that study is that results can be generalised to a wider population if the sample is a representative of the study population. However, a small number of respondents were studied [6]. Despite that the small sample size was randomly selected, the authors indicated as a limitation that they might have missed out on some aspects of malaria control that may be required when generalising their results. Beyond mosquito LSM methods, the western Kenyan study focussed on a number of malaria prevention and control strategies that included use of bed nets and indoor spraying among others. In contrast, a Tanzanian study used mixed (quantitative and qualitative) methods to assess community knowledge and acceptance of larviciding for malaria control [7]. The main advantage of mixed methods is that they demonstrate rigour through triangulation of results from more than one source to get a deeper understanding of the subject matter being investigated [8]. However, this study just focussed on community knowledge of larviciding among several mosquito LSM methods. In addition, a similar method was used by Randell et al. in another Tanzanian study to assess knowledge and practices of environmental management for malaria control [9]. In addition to environmental management methods, the study assessed knowledge of a number of malaria prevention and control methods including use of mosquito coils and burning of local herbs and plants. Few studies, however, have been conducted to analyse determinants of household knowledge of grouped mosquito LSM methods. For example, a Malawian study by Kamndaya et al. analysed determinants of household knowledge of grouped mosquito LSM methods using a cross-sectional household survey [10]. In that study, the authors fell short of assessing determinants of household knowledge of split mosquito LSM methods. Importantly, it was observed in that study that educational status, occupational status and socio-economic factors were determinants of household knowledge of grouped mosquito LSM methods. However, there have been no previous studies known to the authors comparing and contrasting the determinants of household knowledge of split and grouped mosquito LSM methods for malaria prevention and control. In a study of effect of communitydriven larval source management (LSM) and house improvement $(\mathrm{HI})$ on malaria transmission when added to the standard malaria control strategies in Malawi through a cluster randomized trial, McCann et al. combined larviciding as well as removing stagnant water through draining or filling as a form of LSM [11]. Randomized trials are considered gold standard in research as they reduce biases as much as possible [12]. Literature indicates that on top of larviciding as well as draining and/or filling stagnant water, mosquito LSM methods include other forms of habitat modification and habitat manipulation such as clearing of vegetation as well as removal of water-containing vessels [5]. These methods were not considered in that study. In addition, McCann et al. did not assess determinants of grouped LSM methods as their study largely focused on the effect of community-based HI and LSM on malaria parasite prevalence and transmission intensity as measured by entomological inoculation rate (EIR). We used data from a recent empirical research study to provide a

Page 2/9 
comprehensive summary that compares and contrasts the current methods used to assess determinants of household knowledge of split and grouped mosquito LSM methods for malaria prevention and control in a rural Malawian community.

\section{Methods}

\section{Study design}

Data for this study were drawn from a cross-sectional study, Household Knowledge, Perceptions and Practices of Mosquito Larval Source Management for Malaria Prevention and Control in Mwanza district, Malawi, which was published elsewhere [10].

\section{Definition of research variables}

This study uses the methods of Kamndaya et al. and the methods description partly reproduces their wording [10].

\section{Definitions}

a. Household knowledge of grouped mosquito LSM methods: Refers to the household knowledge of combined methods of draining stagnant water, larviciding, clearing grass and bushes as well as clean environment around the home.

1. Household knowledge of split mosquito LSM methods: Refers to the household knowledge of each of the following as a stand-alone method: draining stagnant water, larviciding, clearing grass and bushes as well as clean environment around the home.

2. High-level knowledge of mosquito LSM methods (yes): Refers to either having knowledge of two or more grouped mosquito LSM methods.

3. Low-level knowledge of mosquito LSM methods: Refers to either having knowledge of either none or one of the grouped mosquito LSM methods.

4. No: Not having knowledge of split mosquito LSM methods.

5. Yes: Having knowledge of one split mosquito method.

\section{Statistical analyses}

We conducted a comparative analysis of determinants of household knowledge between split and grouped mosquito LSM methods for malaria prevention and control. Chi-square test was used to compare the distribution of household knowledge of split and grouped mosquito LSM methods. Logistic regression model using enter method (contrast: indictor) was used to examine factors associated with household knowledge of each of the split mosquito LSM methods. The models adjusted for gender and selected socio-demographic factors (excluding pregnancy status). All statistical analyses used SPSS version 18. A detailed analysis of factors associated with household knowledge of grouped mosquito LSM methods are highlighted elsewhere [10].

\section{Ethical considerations}

\section{Ethical approval}

for this study was obtained from the Malawi National Health Science Research Committee (NHSRC) (Approval number: 2158).

\section{Results}

Table 1 shows comparison of household knowledge of each of the split and grouped LSM methods among respondents in Nthache area, Mwanza district. We observed that knowledge of draining stagnant water was lower than high-level knowledge of grouped mosquito LSM methods (32.9\% versus $83.5 \%$, $p=0.000$ ). Our results suggested that knowledge of clearing grass/bushes was lower than high-level knowledge of grouped mosquito LSM methods ( $8.2 \%$ versus $77.7 \%$, $\mathrm{p}=0.000)$. We observed that knowledge of clean environment was lower than high-level knowledge of grouped mosquito LSM methods ( $21.8 \%$ versus $63.8 \%$, $\mathrm{p}=0.000$ ). No significant differences were observed between knowledge of larviciding and high-level knowledge of grouped mosquito LSM methods (4.1\% versus $5.8 \%, \mathrm{p}=0.421)$. 
Table 1

Comparison of household knowledge of split and grouped LSM methods among respondents in Nthache area, Mwanza district

\begin{tabular}{|c|c|c|c|c|c|c|c|c|}
\hline \multirow{2}{*}{$\begin{array}{l}\text { Household knowledge of split mosquito LSM } \\
\text { Methods }\end{array}$} & & \multicolumn{4}{|c|}{ Household knowledge of grouped mosquito LSM methods } & \multirow[t]{2}{*}{$\chi^{2}$} & \multirow[t]{2}{*}{ df } & \multirow[t]{2}{*}{ P-value } \\
\hline & & High-level & $\%$ & Low-level & $\%$ & & & \\
\hline \multirow[t]{2}{*}{ Draining stagnant water } & Yes & 258 & 83.5 & 56 & 32.9 & 124.12 & 1 & 0.000 \\
\hline & No & 51 & 16.5 & 114 & 67.1 & & & \\
\hline \multirow[t]{2}{*}{ Larviciding } & Yes & 18 & 5.8 & 7 & 4.1 & 0.65 & 1 & 0.421 \\
\hline & No & 291 & 94.2 & 163 & 95.9 & & & \\
\hline \multirow[t]{2}{*}{ Clearing grass and bushes around the home } & Yes & 240 & 77.7 & 14 & 8.2 & 212.27 & 1 & 0.000 \\
\hline & No & 69 & 22.3 & 156 & 91.8 & & & \\
\hline \multirow[t]{2}{*}{ Cleaning the environment around the home } & Yes & 197 & 63.8 & 37 & 21.8 & 77.38 & 1 & 0.000 \\
\hline & No & 112 & 36.2 & 133 & 78.2 & & & \\
\hline
\end{tabular}

Table 2 shows comparison of factors associated with household knowledge of each of the split and grouped mosquito LSM methods among respondents in Nthache area, Mwanza district. Respondents without education had 0.43 times less the odds of having knowledge of draining stagnant water than those with primary education (AOR=0.43, 95\% $\mathrm{Cl} 0.26-0.69)$. Respondents from iron-roofed households and the widowed had three times and four times the odds of having knowledge of larviciding than those from grass-thatched households and the married ( $\mathrm{AOR}=3.03,95 \% \mathrm{Cl} 1.26-7.29$ and $\mathrm{AOR}=4.73,95 \% \mathrm{Cl} 1.34-16.73)$, respectively. Respondents engaged in mixed farming (including pastoralists) and businesspersons (including the self-employed) had more than four times and three times the odds whereas those without education and those from mudwalled households had 0.43 times less and 0.47 times less the odds of having knowledge of clearing grass/bushes than crop farmers, those with primary education and dwellers of brickwalled households (AOR=4.33, 95\% $\mathrm{Cl} 2.46-7.63$, $\mathrm{AOR}=3.06,95 \% \mathrm{Cl} 1.44-6.49, \mathrm{AOR}=0.43,95 \% \mathrm{Cl}$ 0.26-0.71 and $\mathrm{AOR}=0.47,95 \% \mathrm{Cl} 0.30-0.74$ ), respectively. Respondents engaged in mixed farming (including pastoralists) and housewives had more than three times and more than two times the odds of having knowledge of clean environment than crop farmers (AOR=3.24, 95\% Cl 1.97-5.33 and $\mathrm{AOR}=2.55,95 \% \mathrm{Cl} 1.03-6.31$ ), respectively. 
Table 2

Comparison of factors associated with household knowledge of split and grouped mosquito LSM methods among respondents in Nthache area, Mwan: Household knowledge of mosquito LSM methods

Split mosquito LSM methods

Grouped

LSM met

\begin{tabular}{|c|c|c|c|c|c|c|c|c|c|c|c|c|c|c|}
\hline & & \multicolumn{3}{|c|}{ Model 1} & \multicolumn{3}{|c|}{ Model 2} & \multicolumn{3}{|c|}{ Model 3} & \multicolumn{3}{|c|}{ Model 4} & Model 5 \\
\hline & & \multicolumn{3}{|c|}{$\begin{array}{l}\text { Draining stagnant } \\
\text { water }\end{array}$} & \multicolumn{3}{|c|}{ Larviciding } & \multicolumn{3}{|c|}{$\begin{array}{l}\text { Clearing grass/bushes } \\
\text { around the home }\end{array}$} & \multicolumn{3}{|c|}{$\begin{array}{l}\text { Clean the environment } \\
\text { around the home }\end{array}$} & $\begin{array}{l}\text { Draining } \\
\text { water }+\mathrm{L} \\
\text { Clearing } \\
+ \text { Clean } t \\
\text { environm } \\
\text { the hom }\end{array}$ \\
\hline Factors & Categories & AOR & $95 \% \mathrm{Cl}$ & $\begin{array}{l}\mathrm{P} \text { - } \\
\text { value }\end{array}$ & AOR & $\begin{array}{l}95 \% \\
\mathrm{Cl}\end{array}$ & $\begin{array}{l}\mathrm{P} \text { - } \\
\text { value }\end{array}$ & AOR & $95 \% \mathrm{Cl}$ & $\begin{array}{l}\mathrm{P} \text { - } \\
\text { value }\end{array}$ & AOR & $95 \% \mathrm{Cl}$ & $\begin{array}{l}\mathrm{P} \text { - } \\
\text { value }\end{array}$ & AOR 9 \\
\hline \multicolumn{15}{|l|}{ Sex } \\
\hline & Female & \multicolumn{3}{|l|}{ Ref } & \multicolumn{3}{|l|}{ Ref } & \multicolumn{3}{|l|}{ Ref } & \multicolumn{3}{|l|}{ Ref } & Ref \\
\hline & Male & 1.23 & $\begin{array}{l}0.76- \\
1.98\end{array}$ & 0.401 & 1.91 & $\begin{array}{l}0.74- \\
4.90\end{array}$ & 0.182 & 0.93 & $\begin{array}{l}0.59- \\
1.48\end{array}$ & 0.771 & 0.98 & $\begin{array}{l}0.65- \\
1.48\end{array}$ & 0.914 & 1.08 \\
\hline
\end{tabular}

Model 5

Marital

status

\begin{tabular}{|c|c|c|c|c|c|c|c|c|c|c|c|}
\hline Married & Ref & & & Ref & & & Ref & & & Ref & \\
\hline Single & 1.46 & $\begin{array}{l}0.46- \\
4.62\end{array}$ & 0.523 & 2.09 & $\begin{array}{l}0.51- \\
8.67\end{array}$ & 0.308 & 1.05 & $\begin{array}{l}0.35- \\
3.19\end{array}$ & 0.931 & 0.43 & $\begin{array}{l}0 \\
1\end{array}$ \\
\hline Widowed & 0.69 & $\begin{array}{l}0.32- \\
1.48\end{array}$ & 0.343 & 4.73 & $\begin{array}{l}1.34- \\
16.73\end{array}$ & 0.016 & 0.45 & $\begin{array}{l}0.19- \\
1.04\end{array}$ & 0.062 & 0.74 & $\begin{array}{l}0 \\
1\end{array}$ \\
\hline Divorced/Separated & 1.49 & $\begin{array}{l}0.68 \text { - } \\
3.31\end{array}$ & 0.318 & 0.82 & $\begin{array}{l}0.10- \\
6.58\end{array}$ & 0.848 & 0.58 & $\begin{array}{l}0.28- \\
1.22\end{array}$ & 0.151 & 0.89 & 0 \\
\hline
\end{tabular}

Educational

status

\begin{tabular}{|c|c|c|c|c|c|c|c|c|c|c|c|}
\hline Primary & Ref & & & Ref & & & Ref & & & Ref & \\
\hline Secondary & 1.21 & $\begin{array}{l}0.59- \\
2.46\end{array}$ & 0.605 & 2.01 & $\begin{array}{l}0.67- \\
6.05\end{array}$ & 0.217 & 1.89 & $\begin{array}{l}0.96- \\
3.76\end{array}$ & 0.067 & 3.54 & $\begin{array}{l}1 \\
8\end{array}$ \\
\hline None & 0.43 & $\begin{array}{l}0.26- \\
0.69\end{array}$ & 0.001 & 1.00 & $\begin{array}{l}0.33- \\
2.98\end{array}$ & 0.994 & 0.43 & $\begin{array}{l}0.26- \\
0.71\end{array}$ & 0.001 & 0.38 & $\begin{array}{l}0 \\
0\end{array}$ \\
\hline Informal/Pre-primary & 0.89 & $\begin{array}{l}0.13- \\
5.89\end{array}$ & 0.900 & 5.59 & $\begin{array}{l}0.49- \\
62.96\end{array}$ & 0.164 & 0.69 & $\begin{array}{l}0.09- \\
5.38\end{array}$ & 0.731 & 0.92 & $\begin{array}{l}0 \\
6\end{array}$ \\
\hline
\end{tabular}

Occupational

status

\begin{tabular}{|c|c|c|c|c|c|c|c|c|c|c|c|}
\hline Crop farming & Ref & & & Ref & & & Ref & & & Ref & \\
\hline $\begin{array}{l}\text { Mixed } \\
\text { farming/Pastoralists }\end{array}$ & 1.38 & $\begin{array}{l}0.81- \\
2.36\end{array}$ & 0.239 & 4.33 & $\begin{array}{l}2.46 \\
-7.63\end{array}$ & 0.000 & 3.24 & $\begin{array}{l}1.97- \\
5.33\end{array}$ & 0.000 & 6.95 & $\begin{array}{l}3 \\
1\end{array}$ \\
\hline $\begin{array}{l}\text { Businessperson/Self- } \\
\text { employed }\end{array}$ & 1.29 & $\begin{array}{l}(0.59- \\
2.83\end{array}$ & 0.511 & 3.06 & $\begin{array}{l}1.44 \\
-6.49\end{array}$ & 0.004 & 1.78 & $\begin{array}{l}0.93- \\
3.43\end{array}$ & 0.084 & 3.61 & $\begin{array}{l}1 \\
8\end{array}$ \\
\hline Unemployed/Student & 0.50 & $\begin{array}{l}(0.09- \\
2.74\end{array}$ & 0.427 & 0.14 & $\begin{array}{l}0.02- \\
1.36\end{array}$ & 0.090 & 1.96 & $\begin{array}{l}0.43- \\
8.94\end{array}$ & 0.384 & 0.57 & $\begin{array}{l}0 \\
3\end{array}$ \\
\hline
\end{tabular}

\section{NOTE:}

Model 1 adjusted for sex, marital status, educational status, occupational status, household wall, household floor and household roof. Age-group, household and energy type were not significant at bivariate level (pregnancy status was excluded)

Model 2 adjusted for sex, marital status, educational status and household roof type. Age-group, occupational status, household ownership, household floor, roof and household energy type were not significant at bivariate level (pregnancy status was excluded)

Model 3 adjusted for sex, marital status, educational status, occupational status and household wall type. Age-group, household ownership, household floor, roof type and household energy type were not significant at bivariate level (pregnancy status was excluded)

Model 4 adjusted for sex and occupational status. Age-group, marital status, educational status, household ownership, household wall, household floor and $\mathrm{t}$ roof, household energy type were not significant at bivariate level (pregnancy status was excluded)

Model 5 adjusted for sex, marital status, educational status, occupational status, household wall, household floor and household roof types. Age-group, hous ownership and household energy type were not significant at bivariate level (pregnancy status was excluded)

Italic values indicate significance of $p$ value $(p \leq 0.05)$ 


\begin{tabular}{|c|c|c|c|c|c|c|c|c|c|c|c|c|}
\hline & \multicolumn{12}{|c|}{ Household knowledge of mosquito LSM methods } \\
\hline & \multicolumn{10}{|c|}{ Split mosquito LSM methods } & \multirow{2}{*}{\multicolumn{2}{|c|}{$\begin{array}{l}\text { Grouped } \\
\text { LSM met } \\
\text { Model } 5\end{array}$}} \\
\hline & \multicolumn{3}{|c|}{ Model 1} & Model 2 & \multicolumn{3}{|c|}{ Model 3} & \multicolumn{3}{|c|}{ Model 4} & & \\
\hline & \multicolumn{3}{|c|}{$\begin{array}{l}\text { Draining stagnant } \\
\text { water }\end{array}$} & Larviciding & \multicolumn{3}{|c|}{$\begin{array}{l}\text { Clearing grass/bushes } \\
\text { around the home }\end{array}$} & \multicolumn{3}{|c|}{$\begin{array}{l}\text { Clean the environment } \\
\text { around the home }\end{array}$} & \multicolumn{2}{|c|}{$\begin{array}{l}\text { Draining } \\
\text { water }+\mathrm{L} \\
\text { Clearing } \\
+ \text { Clean } \mathrm{t} \\
\text { environm } \\
\text { the hom }\end{array}$} \\
\hline Employee & 1.27 & $\begin{array}{l}0.49- \\
3.27\end{array}$ & 0.626 & & 1.50 & $\begin{array}{l}0.63- \\
3.57\end{array}$ & 0.355 & 1.36 & $\begin{array}{l}0.59- \\
3.12\end{array}$ & 0.465 & 0.88 & $\begin{array}{l}0 \\
2\end{array}$ \\
\hline Housewife & 0.43 & $\begin{array}{l}0.17- \\
1.09\end{array}$ & 0.074 & & 0.96 & $\begin{array}{l}0.38- \\
2.45\end{array}$ & 0.939 & 2.55 & $\begin{array}{l}1.03- \\
6.31\end{array}$ & 0.043 & 0.58 & $\begin{array}{l}0 \\
1\end{array}$ \\
\hline Other & 0.85 & $\begin{array}{l}0.09- \\
7.36\end{array}$ & 0.881 & & 0.66 & $\begin{array}{l}0.06- \\
7.44\end{array}$ & 0.733 & 0.49 & $\begin{array}{l}0.05- \\
4.74\end{array}$ & 0.534 & 0.32 & $\begin{array}{l}0 \\
3\end{array}$ \\
\hline
\end{tabular}

Household

wall

\begin{tabular}{lllllllll} 
Brick wall & Ref & \multicolumn{3}{c}{ Ref } & & & Ref \\
Mud wall & 0.63 & $0.39-$ & 0.067 & 0.47 & 0.30 & 0.001 & 0.50 & 0 \\
& & 1.03 & & & -0.74 & & 0 \\
\hline
\end{tabular}

Household

floor

$\begin{array}{llllll}\text { Natural/Earth } & \text { Ref } & & & \text { Ref } \\ \text { Cement/Tiles } & 1.37 & 0.69- & 0.370 & 0 & 1.30 \\ & & 2.74 & & 0 & 2\end{array}$

Household

roof

\begin{tabular}{|c|c|c|c|c|c|c|}
\hline Grass/Thatch & Ref & & & Ref & & Ref \\
\hline Iron sheets & 1.44 & $\begin{array}{l}0.83- \\
2.47\end{array}$ & 0.193 & 3.03 & $\begin{array}{ll}1.26- & 0.014 \\
7.29 & \end{array}$ & 1.17 \\
\hline
\end{tabular}

\section{NOTE:}

Model 1 adjusted for sex, marital status, educational status, occupational status, household wall, household floor and household roof. Age-group, household and energy type were not significant at bivariate level (pregnancy status was excluded)

Model 2 adjusted for sex, marital status, educational status and household roof type. Age-group, occupational status, household ownership, household floor, roof and household energy type were not significant at bivariate level (pregnancy status was excluded)

Model 3 adjusted for sex, marital status, educational status, occupational status and household wall type. Age-group, household ownership, household floor, roof type and household energy type were not significant at bivariate level (pregnancy status was excluded)

Model 4 adjusted for sex and occupational status. Age-group, marital status, educational status, household ownership, household wall, household floor and $\mathrm{r}$ roof, household energy type were not significant at bivariate level (pregnancy status was excluded)

Model 5 adjusted for sex, marital status, educational status, occupational status, household wall, household floor and household roof types. Age-group, hous ownership and household energy type were not significant at bivariate level (pregnancy status was excluded)

Italic values indicate significance of $p$ value $(p \leq 0.05)$

\section{Discussion}

This study compared determinants of household knowledge of split and grouped mosquito LSM methods for malaria prevention and control in a rural community of Malawi. Knowledge is not the only factor that effect prevention and control practices [13], but it is an important prerequisite for the latter. Larval control is an important vector control methods that the majority of people in rural and urban communities need to be aware of. Literature suggests that mosquito larval habitats need treating, draining or filling as frequently as possible in order to disrupt the mosquito life cycle as it takes between 5 to 14 days for them to mature into adult mosquitoes [5]. It is, therefore, important to design and implement health promotion interventions that focus more on disrupting larval habitats in the rural areas.

We highlighted the lack of attention paid to the people without formal education in as far as awareness of draining stagnant water as well as clearing grass and bushes for malaria prevention and control is concerned in rural Malawi. In addition, our results showed significant differences between the knowledge of three (draining stagnant water, clearing grass/bushes and clean environment around the home) split mosquito LSM methods and high-level knowledge of grouped mosquito LSM methods. However, no significant differences between household knowledge of larviciding and high-level knowledge of grouped mosquito LSM methods were observed. It was further observed that the odds of having high-level knowledge of mosquito LSM methods were $62 \%$ less and 
3.54 times higher among respondents without education and secondary education, respectively, than those with primary education. Overall, this shows that determinants of household knowledge for grouped mosquito LSM methods may have obscured those of split methods. Kamndaya et al. observed that twothirds $(65.6 \%)$ and over half $(53.0 \%)$ of the respondents showed knowledge of draining stagnant water as well as clearing grass and bushes for malaria prevention and control, respectively [10]. However, in our analysis of split mosquito LSM methods observed that respondents without formal education were less likely to have knowledge of draining stagnant water as well as clearing grass and bushes for malaria prevention and control than those who attained primary education. This was not an unexpected finding as schools in Malawi offer health education lessons on malaria prevention and control methods that include environmental management for larval habitats. It is worth noting, however, that an Iranian study observed a direct correlation between education levels of the respondents and their practice as well as participation in malaria programs as volunteers [14]. The result from this Malawian study, further, compares to findings from a Cameroonian study that suggested that respondents with secondary/high school/ university level of education were more likely to have a good level of knowledge on malaria than their none/primary level colleagues [15]. Likewise, Kamndaya et al. observed that the odds of having high-level knowledge of grouped mosquito LSM methods were lesser among respondents without formal education as compared to those who attained primary education [10]. No wonder, Kimbi et al. recommended that new strategies for malaria prevention and control should be devised for sensitization messages targeting community members especially those without formal education [15]. Similar results were shared from a Tanzania study which observed that educational attainment was significantly positively correlated with both draining stagnant water and cleaning the environment for malaria prevention and control [9], and Malawian study which reported that uneducated women, women with limited levels of knowledge of malaria in terms of causes, symptoms and prevention measures, rural women and women whose households had no access to any form of media were more likely to have a lower knowledge score for malaria prevention [16]. It is against this background that Mukabana et al. emphasized personal interaction approach based on learning-by-doing when engaging in community-based educational programmes for larval control [7]. Thus, it is necessary to scale up awareness of malaria prevention including mosquito LSM methods among uneducated people in malaria endemic rural areas to eradicate the disease. Further, the odds of having knowledge of clearing grass and bushes around the home were higher among respondents that engaged in mixed farming (including pastoralists) and businesspersons (including the self-employed) as compared to crop farmers. According to [9], people of higher socio-economic status often perform environmental management techniques around their homes. Indeed, this finding should inform authorities to be innovative in finding ways of supporting rural communities with resources to engage in environmental management techniques for malaria prevention and control.

As low as $5.2 \%$ of the respondents knew larviciding for malaria prevention and control [10]. The current analysis observed that the odds of having knowledge of larviciding for malaria and prevention were higher among respondents living in households roofed with iron sheets as compared to those living in grassthatched households. Again, the odds of having knowledge of clearing grass and bush around the home were lesser among respondents living in mudwalled households than those living in brickwalled households. In general, people who live in grass-thatched and mudwalled homes are considered poor [6], as such these results reflect the differences in socio-economic status among respondents in the study area and elsewhere. Another Malawian study highlighted the importance of incentivizing community members to get them involved in larval control [17]. Interestingly, the odds of having knowledge of larviciding for malaria prevention and control were higher among respondents who were widowed as compared to those who were married. It is not clear why this was the case, as such we recommend that further qualitative studies should be conducted to better understand the reasons behind this situation. This recommendation, notwithstanding, it is vital for authorities to work with the widowed in raising awareness of this less known method among the community members including the married residents in the study area to influence practice. Kamndaya et al. observed that less than half (48.9\%) of the respondents knew clean environment for malaria prevention and control (environmental sanitation) [10]. This knowledge was low considering the effectiveness of this method in malaria prevention and control. We, however, observed that the odds of having knowledge relating to clean environment for malaria prevention and control were higher among housewives and respondents that engaged in mixed farming (including pastoralists) than those engaged in crop farming. This result is partly consistent with a previous study that found that women were more likely to clean environment for malaria prevention and control, as compared to men [9]. Culturally, women/housewives look after their homes in SSA. This should, therefore, provide an opportunity for health workers to work with them in raising awareness for this method in areas where malaria is endemic. However, high illiteracy levels among uneducated mothers of children of local Malawian farmers exacerbate malaria cases among their children. Indeed, a Malawian study observed that children of mothers without formal education were more likely to be diagnosed with malaria than children of mothers who had received secondary education [18]. Indeed, the comparison analysis of determinants of household knowledge for split methods may have been obscured or exaggerated by grouped methods as exemplified by marital status and household roof type. This clearly came out in the analysis of determinants of household knowledge for larviciding for malaria prevention and control. It has to be pointed out that a larger sample size is highly recommended when conducting analyses of determinants of household knowledge of larviciding to increase the statistical power as very few respondents showed knowledge of this method in the current study.

In the analysis of determinants of household knowledge of grouped mosquito LSM methods that are reported in our previous publication [10], we identified educational status, occupational and socio-economic status as determinants of high-level knowledge of mosquito LSM methods. However, a comparative analysis shows that determinants of some split mosquito LSM methods were either obscured or exaggerated by those of grouped mosquito LSM methods. For example, an analysis of split mosquito LSM methods revealed that marital status and household roof type were obscured as determinants for knowledge of larviciding for malaria prevention and control when grouped mosquito LSM methods were analysed. Similar observations were reported when draining stagnant water was analysed, as education attainment was the sole determinant for household knowledge of draining stagnant water. We, further, observed that occupation was the sole determinant of clean environment around the home. Further, our study showed significantly higher household knowledge of grouped than split mosquito LSM methods of draining stagnant water, clearing grass/bushes and clean environment among the study population. It is important to note, however, that no significant differences between household knowledge of grouped mosquito LSM methods and knowledge of larviciding were observed. Except for larviciding, we observed significantly higher household knowledge of grouped than split mosquito LSM methods. It is, therefore, recommended that policy for integrated vector management should address determinants of split LSM methods to improve household knowledge.

This study had some limitations which have been clearly outlined elsewhere [10]. In addition to that, it is also important to note that this study used 2018 population projections for Nthache area because at the time this study was being conceptualized and implemented the results of the national census were not 
yet out. These limitations, notwithstanding, a comparative analysis of determinants of household knowledge between split and grouped mosquito LSM methods was done and will help in designing and implementing the environmental management strategies for malaria prevention and control in rural areas of Malawi.

\section{Conclusions}

We identified educational status, occupational and socio-economic status as determinants for household knowledge of grouped mosquito LSM methods. Determinants of household knowledge of split mosquito LSM methods such as larviciding, draining stagnant water and clean environment were either obscured or exaggerated by those of grouped mosquito LSM methods. For example, an analysis of split mosquito LSM methods revealed that marital status and household roof type were obscured as determinants for knowledge of larviciding for malaria prevention and control when grouped mosquito LSM methods were analysed. Similar observations were reported when draining stagnant water was analysed, as education attainment was the sole determinant for household knowledge of draining stagnant water. We, further, observed that occupation was the sole determinant of clean environment around the home. Our study showed significantly higher household knowledge of grouped than split mosquito LSM methods of draining stagnant water, clearing grass/bushes and clean environment among the study population. It is important to note, however, that no significant differences between household knowledge of grouped mosquito LSM methods and knowledge of larviciding were observed. Except for larviciding, we observed significantly higher household knowledge of grouped than split mosquito LSM methods. Policy for integrated vector management should address determinants of split LSM methods to improve household knowledge.

\section{Abbreviations}

AOR: adjusted odds ratio

Cl: confidence interval

COR: crude odds ratio

LSM: larval source management

NHSRC: National Health Sciences Research Committee

NIMR: National Institute for Medical Research

WHO: World Health Organization.

\section{Declarations}

Ethics approval and consent to participate

The study was approved by the Malawi National Health Science Research Committee (NHSRC) at the Ministry of Health (MoH) (NHSRC approval number: 2158)

\section{Consent for publication}

Not applicable

Availability of data and materials

The dataset is available on reasonable request to the corresponding author.

Competing interests

The authors declare that they have no competing interests.

\section{Funding}

Not Applicable

Authors' contributions

DM was involved in the design, development of the study protocol, data management, analysis, and manuscript preparation. MK reviewed the design, study protocol, manuscript, supported with data management and analysis. KL reviewed the draft manuscript. All authors read and approved the final manuscript.

\section{Acknowledgements}

The authors sincerely thank the respondents that participated in the study. Special thanks are reserved for Mr. Pilirani Kanjoka, Mr. Gift Mazalale and Mr. Wongani Mdumuka of Environmental Health Department at Mwanza District Health Office for supporting with data collection. 


\section{References}

[1] World Health Organisation [WHO], WHO Global Technical Strategy for Malaria 2016-2030. Geneva: World Health Organisation, 2015.

[2] D. Dabaro, Z. Birhanu, A. Negash, D. Hawaria, and D. Yewhalaw, "Effects of rainfall, temperature and topography on malaria incidence in elimination targeted district of Ethiopia," Malar. J., vol. 20, p. 104, 2021, doi: 10.1186/s12936-021-03641-1.

[3] WHO Malaria Policy Advisory Committee and Secretariat, "Malaria Policy Advisory Committee to the WHO: conclusions and recommendations of September 2013 meeting," Malar. J., vol. 12, pp. 456-467, 2013.

[4] M. C. Castro, "Malaria Transmission and Prospects for Malaria Eradication: The Role of the Environment," Cold Spring Harb. Perspect. Med., vol. 7, p. a025601, 2017, doi: 10.1101/cshperspect.a025601.

[5] World Health Organisation [WHO], Larval source management: a supplementary measure for malaria vector control: an operational manual. Geneva: World Health Organisation, 2013.

[6] S. Imbahale, U. Fillinger, A. Githeko, and W. Mukabana, "An exploratory survey for malaria prevalence and people's knowledge, attitudes and practices of mosquito larval source management for malaria control in western Kenya," Acta Trop., vol. 115, no. 3, pp. 248-256, 2010, doi: 10.1016/j.actatropica.2010.04.005.

[7] L. E. Mboera, R. A. Kramer, M. L. Miranda, S. P. Kilima, E. H. Shayo, and A. Lesser, “Community knowledge and acceptance of larviciding for malaria control in a Rural District of east-central Tanzania," Int. J. Environ. Res. Public. Health, vol. 11, pp. 5137-5154, 2014, doi: 10.3390/ijerph110505137.

[8] A. Lacey and D. Luff, "Qualitative Research Analysis. The NIHR RDS for the East Midlands/Yorkshire \& the Humber." 2007.

[9] H. F. Randell, K. L. Dickinson, E. H. Shayo, L. E. Mboera, and R. A. Kramer, "Environmental Management for Malaria Control: Knowledge and Perceptions in Mvomero, Tanzania," EcoHealth, vol. 7, pp. 507-516, Aug. 2010.

[10] M. Kamndaya, D. Mfipa, and K. Lungu, "Household knowledge, perceptions and practices of mosquito larval source management for malaria prevention and control in Mwanza district, Malawi: a cross-sectional study," Malar. J., vol. 20, no. 150, 2021, doi: 10.1186/s12936-021-03683-5.

[11] R. S. McCann et al., "The effect of community-driven larval source management and house improvement on malaria transmission when added to the standard malaria control strategies in Malawi: a cluster-randomized controlled trial," Malar. J., vol. 20, no. 232, May 2021, doi: https://doi.org/10.1186/s12936021-03769-0.

[12] E. Harriton and J. J. Locascio, "Randomized controlled trials - the gold standard for effective research," BJOG, vol. 125, no. 13, Dec. 2018.

[13] G. Dhawan, N. Joseph, P. S. Pekow, C. A. Rogers, K. C. Poudel, and M. T. Bulzacchelli, "Malaria-related knowledge and prevention practices in four neighbourhoods in and around Mumbai, India: a cross-sectional study," Malar. J., vol. 13, p. 303, 2014.

[14] A. Hanafi-Bojd et al., "Knowledge, attitudes and practices regarding malaria control in an endemic area of Southern Iran," Southeast Asian J. Trop. Med. Public Health, vol. 42, no. 3, pp. 491-501, 2011.

[15] H. K. Kimbi, S. B. Nkesa, J. L. Ndamukong-Nyanga, I. U. Sumbele, J. Atashili, and M. B. Atanga, "Knowledge and perceptions towards malaria prevention among vulnerable groups in the Buea Health District, Cameroon," BMC Public Health, vol. 14, no. 1, pp. 883-891, 2014.

[16] A. Sixpence et al., "Levels of knowledge regarding malaria causes, symptoms and prevention measures among Malawian women of reproductive age," Malar. J., vol. 19, no. 225, 2020, doi: 10.1186/s12936-020-03294-6.

[17] S. Gowelo, R. S. McCann, C. J. Koenraadt, W. Takken, H. van den Berg, and L. Manda-Taylor, "Community factors affecting participation in larval source management for malaria control in Chikwawa District, Southern Malawi," Malar. J., vol. 19, no. 195, p. https://doi.org/10.1186/s12936-020-03268-8, 2020, doi: https://doi.org/10.1186/s12936-020-03268-8.

[18] E. Chilanga, D. Collin-Vezina, H. Macintosh, C. Mitchell, and K. Cherney, "Prevalence and determinants of malaria among children of local farmers in Central Malawi," Malar. J., vol. 19, no. 308, 2020, doi: 10.1186/s12936-020-03382-7.

\section{Supplementary Files}

This is a list of supplementary files associated with this preprint. Click to download.

- Dataset.sav 